\title{
Gui-Pi-Wan extract acts as a radioprotective agent
}

\author{
XU Ping ${ }^{1 *} \&$ JIANG EnJin ${ }^{2}$ \\ ${ }^{1}$ Department of Pharmacy, Xinxiang Medical University, Xinxiang 453003, China; \\ ${ }^{2}$ Institute of Radiation Medicine, Academy of Military Medical Sciences, Beijing 100850, China
}

Received December 31, 2010; accepted April 1, 2011

\begin{abstract}
The radioprotective effects of 6 Gui-Pi-Wan extracts were investigated by examining cell viability and 30-d survival of mice after total-body ${ }^{60} \mathrm{Co}$ irradiation. Pretreatment with Gui-Pi-Wan precipitate by water extraction and alcohol precipitation (PWA) prior to irradiation resulted in significantly higher cell survival and lower apoptosis rates at $24 \mathrm{~h}$ after 5 Gy radiation, and increased 30-d survival in mice after exposure to a potentially lethal dose of $8 \mathrm{~Gy}$. These results collectively indicate that PWA of Gui-Pi-Wan extracts is an effective radioprotective agent.
\end{abstract}

Gui-Pi-Wan, PWA, cell survival, apoptosis rate, survival rate

Citation: $\quad$ Xu P, Jiang E J. Gui-Pi-Wan extract acts as a radioprotective agent. Chinese Sci Bull, 2011, 56: 2109-2113, doi: 10.1007/s11434-011-4529-5

The increasing use of ionizing radiation in various aspects of human life, especially in cancer radiotherapy, food preservation, agriculture, industry, and power generation, means that there is a need to develop effective and nontoxic radioprotective agents. The currently available agents are associated with many drawbacks, including high cost, side effects and toxicity, and people have therefore started to investigate the anti-radiation properties of natural products. We have isolated a series of active ingredients from natural anti-radiation substances, such as polysaccharides [1-6], flavonoids [7-11], polyphenols [12-14], saponins [15-18], alkaloids [19,20], and peptide compounds [21,22].

Gui-Pi-Wan and Gui-Pi-Tang contain the same drugs, but in different dosage forms. The "Ji Sheng Formula" for Gui-Pi-Tang was written by Yonghe Yan in the Song Dynasty, and consists of Astragalus membranaceus, licorice (broil), ginseng, Angelica, Chinese Atractylodes, wild jujube, Radix aucklandiae, Radix polygalae and dried longan pulp. Yao et al. [23] observed the outcomes in 86 patients with advanced esophageal cancer who were treated with Gui-Pi-Tang combined with concurrent chemoradiation. Gui-PiTang reduced the radiotherapy- and chemotherapy-

*Corresponding author (email: 13273730271@163.com) induced damage to the bone marrow and immune function, protected the body's immunity, improved the quality of life of cancer patients after radiotherapy and chemotherapy, and may also have had some inhibitory effect on tumor metastasis. Li et al. [24] reported an overall improvement rate of $88.3 \%$ in 40 patients with neutropenia after chemotherapy treated with Gui-Pi-Tang combined with Fu-zheng-he- ji. However, no study has yet reported on the radioprotective activity of its extract. The present study therefore focused on the use of Gui-Pi-Wan precipitate by water extraction and alcohol precipitation (PWA) as a radioprotective agent in experimental cell and animal models.

Gui-Pi-Wan extracts were used to reduce the required dosage and to enhance drug efficacy. The screening of 6 extracts of the classic Chinese herbal formula Gui-Pi-Wan for anti-radiation activities in this study will form the basis for further screening of components with radioprotective activities.

\section{Materials and methods}

\subsection{Materials}

(i) Animals. Male KM mice (4-6 weeks old, weighing 
18-22 g) were purchased from the Experimental Animal Center of Xinxiang Medical University. Animals were housed at 10 per cage with ad libitum access to water and food pellets.

(ii) Drugs and reagents. Gui-Pi-Wan was manufactured by Wanxi Pharmaceutical Co., Ltd (Henan, China; product batch number 100903, production date 10.09.10); Cell Counting Kit-8 (CCK-8) was manufactured by Dojindo Laboratories (Kumamoto, Japan); "523" was obtained from Institute of Radiation Medicine (Beijing, China); Binding buffer was from an Annexin V-FITC apoptosis detection kit (Baosai Biotechnology Co., Ltd, China).

(iii) Cell culture. V79 Chinese hamster lung fibroblast cells were cultured adherently in DMEM medium containing $10 \%$ fetal bovine serum, $100 \mathrm{U} / \mathrm{mL}$ penicillin and 100 $\mathrm{U} / \mathrm{mL}$ streptomycin at $37^{\circ} \mathrm{C}$ in a humidified atmosphere of $5 \% \mathrm{CO}_{2}$.

\subsection{Preparation of Gui-Pi-Wan extracts}

(i) Preparation of water extract (WE). Gui-Pi-Wan rough powder was extracted using 10 times the amount of boiling water. The extract was filtered through four layers of gauze. The entire process was repeated twice. The combined filtrate was centrifuged at $2000 \mathrm{r} / \mathrm{min}$ for $20 \mathrm{~min}$, and concentrated under reduced pressure. Half of the liquid obtained was vacuum evaporated to produce a powder, which was redissolved in water just before oral administration.

(ii) Preparation of supernatant by water extraction and alcohol precipitation (SWA). The remaining half of the concentrated solution was cooled to room temperature and mixed with alcohol to an alcohol content of $70 \%$. The mixture was refrigerated for $24 \mathrm{~h}$, filtered, concentrated, and vacuum evaporated to produce a powder, which was redissolved in water just before oral administration.

(iii) Preparation of PWA. Filtered sediment from Section 1.2 (ii) was vacuum evaporated to produce a powder, which was redissolved in water just before oral administration.

(iv) Preparation of ethanol extracts (EE). Gui-Pi-Wan rough powder was extracted using 10 times the amount of $70 \%$ ethanol, and the extract was filtered through four layers of gauze. The entire process was repeated twice. The combined filtrate was centrifuged at $2000 \mathrm{r} / \mathrm{min}$ for $20 \mathrm{~min}$, and concentrated under reduced pressure. Half of the liquid obtained was vacuum evaporated to produce a powder, which was redissolved in water just before oral administration.

(v) Preparation of supernatant by alcohol extraction and water precipitation (SAW). The other half of the concentrated solution of ethanol extract was cooled to room temperature and mixed with an appropriate amount of water. The mixture was refrigerated for $24 \mathrm{~h}$, filtered, concentrated, and vacuum evaporated to produce a powder, which was redissolved in water just before oral administration. (vi) Preparation of precipitate by alcohol extraction and water precipitation (PAW). Filtered sediment from (v) was vacuum evaporated to produce a powder, which was redissolved in water just before oral administration.

\subsection{Irradiation}

Cells were irradiated at room temperature with ${ }^{60} \mathrm{Co} \gamma$-rays at a dose rate of $227.7 \mathrm{cGy} / \mathrm{min}$ for a total dose of $5 \mathrm{~Gy}$. The animals were restrained in holders and exposed to 8 Gy total-body ${ }^{60} \mathrm{Co} \gamma$ radiation at a dose rate of $228.27 \mathrm{cGy} / \mathrm{min}$ to determine their 30 -d survival rate.

\subsection{Radioprotective effects of extracts on V79 cells}

V79 cells $\left(1 \times 10^{5}\right.$ cells $\left./ \mathrm{mL}\right)$ in logarithmic growth phase were seeded in 96-well plates containing $100 \mu \mathrm{L} /$ well of drug at a final concentration of $1000 \mu \mathrm{g} / \mathrm{mL}$ (referred to as the drug groups). The drug groups were compared with control unirradiated cells and with irradiated, untreated cells. After $24 \mathrm{~h}$, cells were irradiated with ${ }^{60} \mathrm{Co}$ at a dose of 5 Gy. CCK-8 solution $(10 \mu \mathrm{L})$ was added to each well at 24 $\mathrm{h}$ after irradiation. The absorbance of each well at $490 \mathrm{~nm}$ was determined after a further $4 \mathrm{~h}$, using a multifunctional microplate reader [25].

\subsection{Radioprotective effects of different concentrations of PWA in V79 cells}

V79 cells $\left(1 \times 10^{5}\right.$ cells $\left./ \mathrm{mL}\right)$ in logarithmic growth phase were seeded in 96-well plates containing $100 \mu \mathrm{L} /$ well of drug at final drug concentrations of 1000, 500, 100, 50, or $25 \mu \mathrm{g} / \mathrm{mL}$ (referred to as the drug groups). These were compared with control unirradiated cells and with irradiated, untreated cells. After $24 \mathrm{~h}$, cells were irradiated with ${ }^{60} \mathrm{Co}$ at a dose of 5 Gy. CCK-8 solution $(10 \mu \mathrm{L})$ was added to each well at $24 \mathrm{~h}$ after irradiation. The absorbance of each well was determined after a further $4 \mathrm{~h}$, using a multifunctional microplate reader at $490 \mathrm{~nm}$.

\subsection{Detection of apoptosis by Annexin V-fluorescein isothiocyanate (FITC)/propidium iodide (PI) double-staining method}

V79 cells $\left(1 \times 10^{6}\right.$ cells $)$ in logarithmic growth phase were seeded in 6-well culture plates at a drug concentration of $1000 \mu \mathrm{g} / \mathrm{mL}$, according to the results of the experimental screening. After $24 \mathrm{~h}$, cells were irradiated with ${ }^{60} \mathrm{Co}$ at a dose of $5 \mathrm{~Gy}$. Cells from the normal (unirradiated), irradiated (untreated), and drug groups were collected at $24 \mathrm{~h}$ after irradiation and centrifuged at $1000 \mathrm{r} / \mathrm{min}$ for $10 \mathrm{~min}$. The supernatant was removed, and cells were resuspended in $200 \mu \mathrm{L}$ binding buffer after washing twice with precooled phosphate-buffered saline. Annexin V-FITC $10 \mu \mathrm{L}$ 
was added to the cells. The cell suspension was gently mixed and incubated in the dark for $15 \mathrm{~min}$ at room temperature. A total of $300 \mu \mathrm{L}$ binding buffer and $5 \mu \mathrm{L}$ PI were added, and the samples were analyzed by flow cytometry.

\subsection{Determination of 30-d survival rate}

Mice adapted to the environment were divided into normal (unirradiated), irradiated (untreated), positive control (treated with the known radioprotective agent "523"), and drug treatment groups. All drugs were administered orally. Mice in the normal and irradiation groups were given distilled water, and mice in the treatment groups received the appropriate drugs, as indicated in Table 1. All mice were observed for $30 \mathrm{~d}$ after irradiation.

\subsection{Statistical analysis}

Data were expressed as mean \pm standard deviation (SD). The significance of differences between mean values for groups were analyzed using SPSS-16 (IBM, USA). The means of the treated groups were compared with those of the radiation-alone and unirradiated groups. A value of $P<$ 0.05 was considered to be statistically significant.

\section{Results}

\subsection{Radioprotective effects of Gui-Pi-Wan extracts in V79 cells}

The effects of 6 different extracts of Gui-Pi-Wan (1000 $\mu \mathrm{g} / \mathrm{mL}$ ) in V79 cells were tested. The survival rates at $24 \mathrm{~h}$ after irradiation are shown in Figure 1. PWA significantly improved the survival rate of irradiated cells, while the other extracts had negative effects on cell survival.

\subsection{Radioprotective effects of different concentrations of PWA in V79 cells}

The effects of different concentrations of PWA on the survival of V79 cells were examined. The survival rates at $24 \mathrm{~h}$ after irradiation are shown in Figure 2. The survival rates of the irradiated cells gradually increased with increasing concentrations of PWA. The survival rate was highest at a concentration of $1000 \mu \mathrm{g} / \mathrm{mL}$, and this was therefore recommended as the final concentration.

Table 1 Experimental design

\begin{tabular}{ccccc}
\hline Drug delivery & $\begin{array}{c}\text { Time } \\
\text { (d) }\end{array}$ & $\begin{array}{c}\text { Positive drug dose } \\
\text { (agent "523") }\end{array}$ & $\begin{array}{c}\text { Dose of } \\
\text { irradiation } \\
\text { (Gy) }\end{array}$ & $\begin{array}{c}\text { Dose of } \\
\text { PWA (mg } \\
\left.\mathrm{kg}^{-1}\right)\end{array}$ \\
\hline Before irradiation & 6 & $24 \mathrm{~h} ; 5 \mathrm{mg} / \mathrm{kg}$ \\
$\begin{array}{c}\text { After irradiation } \\
\begin{array}{c}\text { Before irradiation+ } \\
\text { after irradiation }\end{array}\end{array}$ & $6+6$ & $\begin{array}{c}24 \mathrm{~h} ; 2.5 \mathrm{mg} / \mathrm{kg}+ \\
\text { Within } 3 \mathrm{~h} ; 2.5 \mathrm{mg} / \mathrm{kg}\end{array}$ & 8 & 500 \\
\hline
\end{tabular}

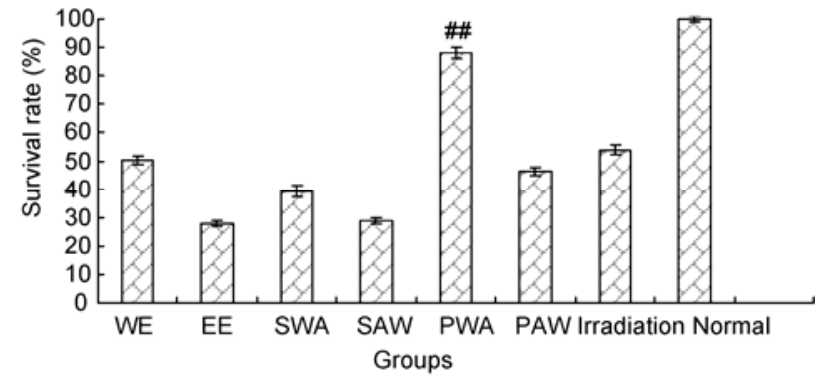

Figure 1 Survival rates of V79 cells treated with 6 different extracts of Gui-Pi-Wan. \#\#, $P<0.01$ compared with irradiation alone.

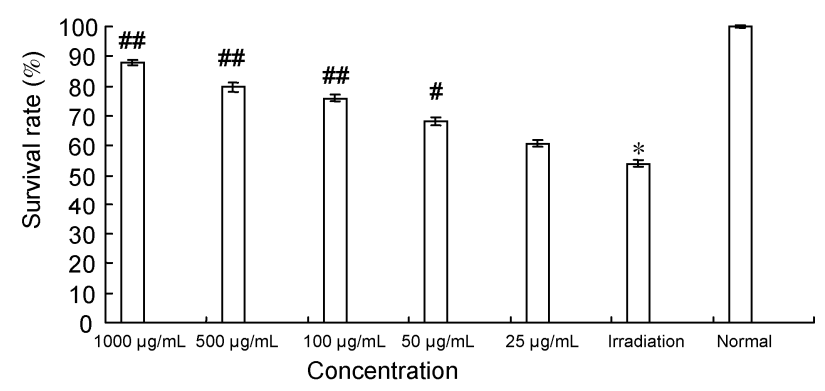

Figure 2 Survival rates of V79 cells treated with PWA. \#, $P<0.05$ compared with irradiation alone; \#\#, $P<0.01$ compared with irradiation alone; *, $P<0.01$ compared with normal.

\subsection{Detection of apoptosis by Annexin V-FITC/PI double-staining method}

The effects of the 6 different extracts of Gui-Pi-Wan on apoptosis were investigated. The apoptosis rates at $24 \mathrm{~h}$ after irradiation are shown in Figure 3. Irradiation increased the apoptosis rate to $40 \%$, while pretreatment with PWA before 5 Gy irradiation significantly reduced the rate of apoptosis to $10 \%$, compared with the irradiation group. The other extracts had no effect on the apoptosis rate.

\subsection{Observation of 30-d survival rate in mice}

The 30-d survival rates of mice are shown in Figure 4. Pretreatment with PWA improved the survival rate by $30 \%$, compared with untreated irradiated animals. The survival rates in the groups treated with the other five extracts were lower than that in the untreated irradiation group. PWA therefore demonstrated a radioprotective function, while the other five extracts had negative effects in terms of radiation
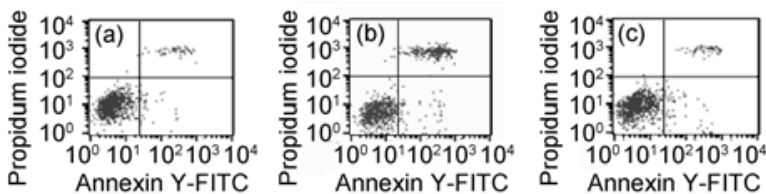

Figure 3 Apoptosis rates in V79 cells after 24-h irradiation. (a) Unirradiated group; (b) irradiation group; (c) pretreatment with PWA before irradiation $(P<0.01$ compared with irradiation group $)$. 

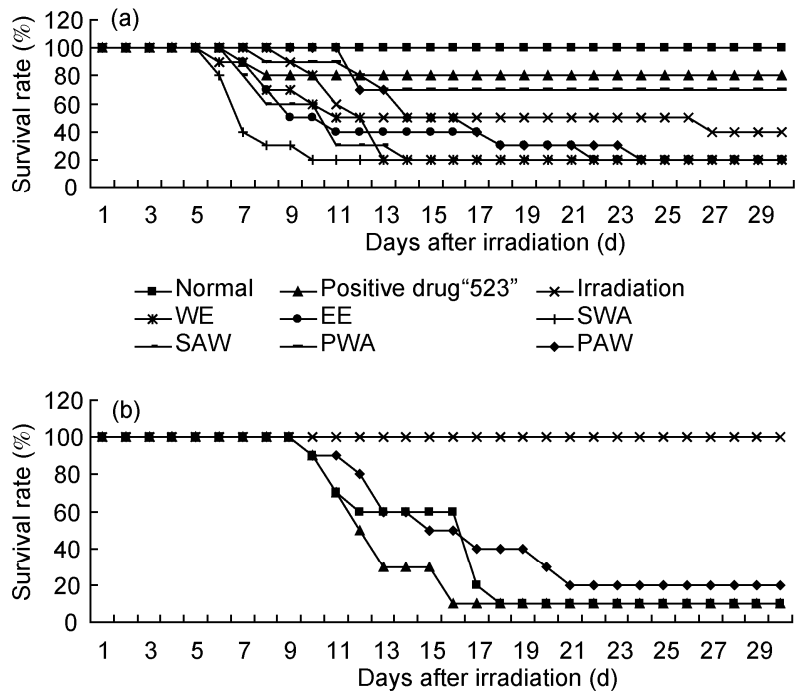

$\rightarrow-$ Irradiation $\rightarrow-$ Positive drug "523" $\_$PWA $\star$ Normal

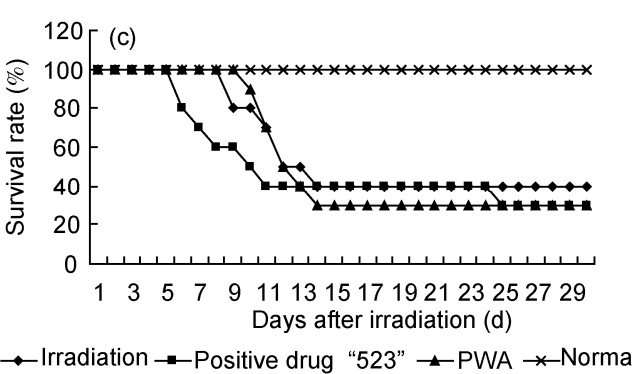

Figure 4 Survival rates of mice treated with Gui-Pi-Wan extracts. (a) Administration of six extracts before irradiation; (b) administration of PWA after irradiation; (c) administration of PWA before and after irradiation.

protection. Administration of PWA after irradiation resulted in a survival rate of $10 \%$, compared with $30 \%$ in untreated irradiated animals. PWA administered before and after irradiation resulted in a survival rate of $20 \%$ compared with $40 \%$ in untreated irradiated animals. These results indicate that pretreatment with PWA is needed to realize its radioprotective activity.

\section{Discussion and conclusions}

Exposure to ionizing radiation significantly decreased cell survival and increased apoptosis rates in irradiated cells in dose-dependent manners. PWA at a dose of $1000 \mu \mathrm{g} / \mathrm{mL}$ significantly prevented cell damage $(P<0.01)$. Similarly, exposure of mice to radiation at $8 \mathrm{~Gy}$ also had adverse effects, and pretreatment with PWA increased the survival rate to $70 \%$, compared with $40 \%$ in the untreated irradiation group. Although PWA was based on the WE of Gui-PiWan, PWA showed good anti-radiation efficacy, while WE and the other four extracts had negative radioprotective effects. Overall, these results suggest that further studies are needed to investigate the potent radioprotective effects of PWA.
PWA contains ingredients including Astragalus polyose, and Atractylodes, Angelica, and Poria cocos polysaccharides. The polysaccharide content of PWA determined by UV spectrophotometry was $83 \%$. Previous studies have shown that the active polysaccharide ingredients in natural medicines are beneficial in resisting irradiation; e.g., Rieh et al. [26] found that the administration of lipopolysaccharide before irradiation protected the bone marrow and small intestine. Jiang et al. [27] found that Astragalus polyose significantly reduced liver lipid peroxidase levels in irradiated mice, and significantly increased superoxide dismutase and catalase activities, in association with promotion of free-radical scavenging, inhibition or blocking of lipid peroxidation, and increased antioxidant capacity. Optimum protection by these natural ingredients can be achieved at non-toxic concentrations, giving them an advantage over thiol tissue-protective agents, such as amifostine, that are currently used during cancer radiotherapy.

1 Il'in L A, Andrianova I E, GIushkov V A, et al. Medical-prophylactic properties of the low-molecular-weight chitosan at environmental radiation injury. Radiat Biol Radioecol, 2004, 44: 547-549

2 Wang Z W, Zhou J M, Huang Z S, et al. Aloe polysaccharides mediated radioprotective effects through the inhibition of apoptosis. Radiat Res, 2004, 45: 447-454

3 Fan L S, Gong C R, Zhang S H. Animal experiment of auricularia polysaccharide anti-radiation effect. J Nutr, 2005, 27: 525-527

4 Wu X M, Yang M L, Huang X L, et al. Laminaria radioprotection and apoptosis of spleen cell. Wuhan Univer J Med Sci, 2004, 25: 239

5 Subramanian M, Chintalwar G, Chattopadhyay S. Antioxidant properties of a Tinospora cordifolia polysaccharide against iron-mediated lipid damage and gamma-ray induced protein damage. Reduct-oxid Rep, 2002, 7: 137-143

6 Song J Y, Han S K, Bae K G, et al. Radioprotective effects of ginseng, an immunomodulator. Radiat Res, 2003, 159: 768-774

7 Liu L H, Wan X C, Li D X. QSAR research of antioxidant activity of flavonoids. J Anhui Agri Univer, 2002, 29: 265-270

$8 \mathrm{Wu} \mathrm{J}$ Q, Jin $\mathrm{H}, \mathrm{Xu} \mathrm{Z} \mathrm{Q}$, et al. Genistein experimental study of radiation effect. Chin J Radiol Health, 2004, 13: 170-172

9 Zielonka J, Gebicki J, Grynkiewicz G. Radical scavenging properties of genistein. Free Radical Biol Med, 2003, 35: 958-965

10 Li D Y, Zhou Y Z, Yu Y L, et al. Anti-radiation effect research of Ginkgo biloba flavonoids. J Nutr, 2004, 26: 220-222

11 Devi P U, Bisht K S, Vinitha M. A comparative study of radioprotection by ocimum flavonoids and synthetic aminothiol protectors in the mouse. Br J Radiol, 1998, 71: 782-784

12 Hibasami H, Jin Z X, Hasegawa M, et al. Oolong tea polyphenol extract induces apoptosis in human stomach cancer cells. Anticancer Res, 2000, 20: 4403-4406

13 Wang Q J, Wang Y S, He L, et al. Anti-radiation effect research of Tu polyphenol and components of Ginkgo biloba. Nucl Technol, 2004, 27: 148-150

14 Lv Q J, Wen L Q, Zhang M, et al. Radiation protection of resveratrol and its molecular mechanism. Chin J Radiol Med Prot, 2004, 24: 21-22

15 Kim S H, Son C H, Nah S Y. Modification of radiation response in mice by Panax Ginseng and diethyldithioearbamate. In Vivo, 2001, 15: 407-411

16 Li T G, Allison R R, O'Brien K F, et al. Ginseng reduces the micronuclei yield in lymphocytes after irradiation. J Xing Xiang Med Coll, 2004, 21: 75-84

17 Kuinar M, Sharma M K, Saxena P S. Radioprotective effect of Panax Ginseng on the phosphate and lipid pemxidation level in text of 
Swiss Albino mice. Biol Pharm Bull, 2003, 3: 308-312

18 Chen J, Wang C Y, Yu L P, et al. Effect of soyasaponin on cytogenetic damage induced by ionizing radiation. J Prac Oncol, 1995, 9: 77

19 Liang L, Yang Y J, Li X F. Protective effect of sophom alopecurades on sub-chronic radiation injury in mice. Trad Chin Med Pharmacol Clin, 2002, 18: 16-17

20 Makarchenko A E, Utkina N K. UV-stability and UV-protective activity of alkaloids from the marine sponge Zyzzya fuliginosa. Chem Nat Compd, 2006, 42: 78-81

21 Zhu Y M, Zhong J Y. The protective effect of Hpp on acute radiation injury. Chin Pub Health, 2004, 20: 1349-1350

22 Yang W C. Melittin isolation, purification and mechanism of anti-radiation. Master Dissertation. Fuzhou: Fujian Agriculture and Forestry University, 2007
23 Yao W H, Hua Q L, Wu J Q. Efficacy observation of Gui-Pi-Tang combined with concurrent radiotherapy and chemotherapy in advanced esophageal cancer. Trad Chin Med, 2006, 36: 81-99

24 Li P X, Jia Y J, Jia Y Z. Clinical observation of Fu-Zheng-He-Ji mixed with Gui-Pi-Tang treatment in leucopenia after chemotherapy. Tianjin Trad Chin Med, 2005, 4: 344

25 Xu S Y, Bian R L, Chen X. Pharmacology Experimental Methodology. Beijing: People's Medical Publishing House, 2003

26 Rieh T, Cohn S, Tessner T, et al. Lipopolysaccharide is radioprotective in the mouse intestine through a prostaglandin-mediated mechanism. Gastroenterology, 2000, 118: 1106-1116

27 Jiang S Q, Ye F, Su S J, et al. Radioprotective effect and the mechanism of yellow mushroom polysaccharide. Chin Radiat Health, 2001, 10: $67-68$

Open Access This article is distributed under the terms of the Creative Commons Attribution License which permits any use, distribution, and reproduction in any medium, provided the original author(s) and source are credited. 